\title{
Corticosteroids for pneumonia: is the saga ending?
}

by Marco Confalonieri

The Star War saga: a famous film series created by George Lucas.

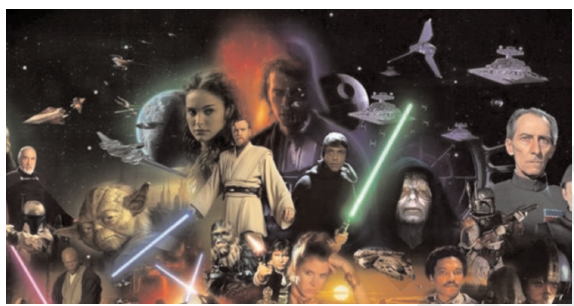

Community acquired pneumonia (CAP) is one of the most common reasons for hospital admission, accounting for more than 1 million admissions each year in the United States, and it is the leading cause of sepsis and ARDS. CAP is associated with considerable short- and long-term morbidity and mortality, particularly in older adult patients and those with significant co-morbidities. A number of studies on CAP, sepsis, and ARDS showed that a dysregulated prolonged inflammatory host response predicts in-hospital and long-term mortality risk. Several studies on corticosteroids for these common acute illness have been replicated with controversial results for some decades now. This is not surprising at all, given that in the daily clinical practice, corticosteroids are the immunomodulatory drug of choice worldwide. These inexpensive agents mimic the response to stress, have a well-known adverse effect profile, but have been used with very different dose regimens, timing, and disease severity. The "corticosteroids saga" begins early in the ' $80 \mathrm{~s}$, thanks to two prospective randomized clinical trials (RCT) on the effects of two-days high dose corticosteroids respectively in patients with septic shock and ARDS (1,2). Both studies were published on the most read scientific journal of clinical medicine and both reported global negative results in spite of a temporary reversal respectively of septic shock and ARDS $(1,2)$. A deeper insight of the corticosteroids biological effects pushed the clinical researchers to use different dose regimen and clinical indications. In the '90s, Meduri and Annane began to use prolonged low dose corticosteroids respectively in patients with ARDS and sepsis reporting positive results on mortality and complications $(3,4)$. These results in sepsis and ARDS were confirmed by several Authors, but others firmly contrasted them. Severe CAP is the most common cause of sepsis and ARDS, and the clinical pictures of severe CAP, sepsis, and ARDS may overlap. We had the opportunity to publish the first RCT (5) on the use of prolonged low dose corticosteroids in patients with severe CAP, most out of them with sepsis and ARDS, showing an encouraging effect on 30 days-mortality in comparison with placebo. The relatively small sample size of our study (5), and the decision to interrupt the trial after a sequential interim analysis in order to reduce the number of patients to "inferior" treatment when treatment-related outcome differences emerged provoked some criticism. Particularly, after the publication of our paper on the blue journal we received a letter humorously entitled "Stop right there... I gotta know right now!", clearly stating skepticism about the significance of our results and making a parody of our sequential trial design (6). Among the subsequent studies, only a single RCT (7) failed to demonstrate any clinical advantage of adding corticosteroids to antibiotics in mild to moderate CAP, but this was the obvious consequence of having any or scarce systemic inflammation. Finally, two very recent and large RCT published on the Lancet and JAMA (8, 9) reported further convincing positive results on the use of corticosteroids in severe CAP supporting the idea that we are approaching the end of the saga. Blum et al. (8) showed that 7 days corticosteroids regimen in patients with CAP admitted to hospital may shorten time to clinical stability without an increase of complications. Torres et al. (9) found that corticosteroids in patients with severe CAP improved the primary end point, which was a composite outcome of treatment failure defined as development of shock, need for mechanical ventilation, death, radiographic progression, persistence of severe respiratory failure, and shock. These results support the hypothesis that beneficial effects of corticosteroids impact the shock component of severe CAP. Data from the seven main RCT, accounting for 1500 adults with CAP, clearly showed that adjunct treatment with corticosteroids reduced the length of hospital stay, time to clinical stability, need for mechanical ventilation, and mortality without significant adverse effects (10). So, to date the saga of corticosteroids using in pneumonia seems really come to the end with no more need for parodies regarding RCTs results. Actually, only the American parodist Alfred "Weird Al" Yankovic may still sing "The saga begins" (Figure 1) with lyrics that humorously summarize the plot of the film Star Wars episode (11). 


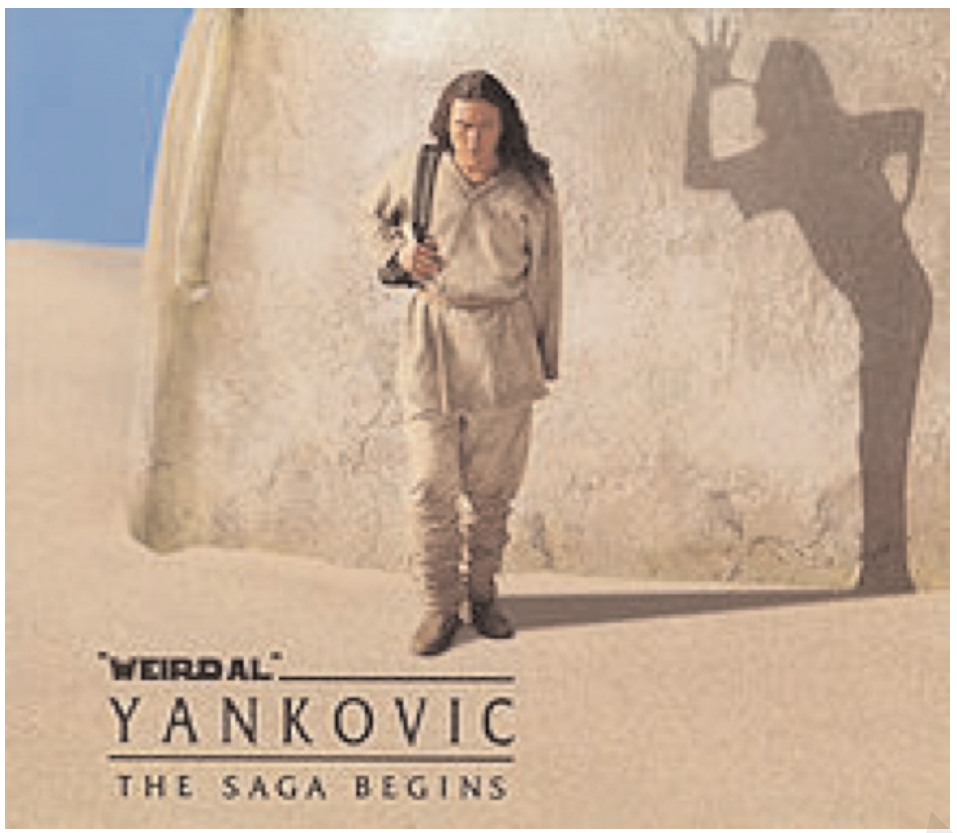

Figure 1 - "Weird Al" Yankovic - The saga begins - Music Corp. of America Inc., Benny Bird Co. Inc.

\section{References}

1. Sprung $\mathrm{CL}$, et al. The effects of high-dose corticosteroids in patients with septic shock. $\mathrm{N}$ Engl $\mathrm{J}$ Med. 1984;311:1137-43.

2. Bernard GR, et al. High-dose corticosteroids in patients with the adult respiratory distress syndrome. $\mathrm{N}$ Engl $\mathrm{J}$ Med. 1987;317:1565-70.

3. Meduri GU, et al. Effect of prolonged methylprednisolone therapy in unresolving acute respiratory distress syndrome: a randomized controlled trial. JAMA. 1998;280:159-165.

4. Annane D, et al. Effect of treatment with low doses of hydrocortisone and fludrocortisone on mortality in patients with septic shock. JAMA. 2002;288:862-71.

5. Confalonieri $\mathrm{M}$, et al. Hydrocortisone infusion for severe community-acquired pneumonia: a preliminary randomized study. Am J Respir Crit Care Med. 2005;171:242-248.

6. Scales DC, et al. "Stop right there...I gotta know right now!" Do steroids really help for CAP? Am J Respir Crit Care Med. 2005;172:643-4.

7. Snijders D, et al. Efficacy of corticosteroids in community-acquired pneumonia: a randomized double-blind clinical trial. Am J Respir Crit Care Med. 2010;181:975-82.

8. Blum CA, et al. Adjunct prednisone therapy for patients with community-acquired pneumonia: a multicentre, double-blind, randomised, placebo-controlled trial. Lancet. 2015 Jan 16.

9. Torres A, et al. Effect of corticosteroids on treatment failure among hospitalised patients with severe communityacquired pneumonia and high inflammatory response: a randomized clinical trial. JAMA. 2015;313:677-86.

10. Annane D. Corticosteroids and pneumonia: time to change practice. Lancet. 2015 Jan 16.

11. "Weird Al" Yankovic - The Saga Begins - Official music video on YouTube. 